\title{
PENERAPAN KONSEP FINITE STATE AUTOMATA PADA SIMULASI ALAT PELIPAT PAKAIAN OTOMATIS
}

\author{
Ricko Anugrah Mulya Pratama', Dedi Irawan², Eni Heni Hermaliani', \\ Windu Gata ${ }^{4}$, Tuti Haryanti ${ }^{5}$ \\ 1,2,3,4Program Studi Ilmu Komputer, Universitas Nusa Mandiri, Jakarta, Indonesia \\ ${ }^{5}$ Program Studi Sistem Informasi, Universitas Nusa Mandiri, Jakarta, Indonesia \\ 114207093@nusamandiri.ac.id, ${ }^{2} 14207097 @$ nusamandiri.ac.id, ${ }^{3}$ eni_h@nusamandiri.ac.id, \\ 4windu@nusamandiri.ac.id, ${ }^{5}$ tuti@nusamandiri.ac.id
}

\begin{abstract}
ABSTRAK
Kebutuhan primer setiap manusia adalah sandang, pangan dan papan, sehingga ketiga aspek tersebut merupakan indikator standar kehidupan minimum seseorang atau komunitas. Sandang (pakaian) merupakan kebutuhan yang paling mendasar untuk setiap manusia sebagai makhluk sosial. Kegiatan melipat pakaian merupakan hal yang sangat umum dilakukan setiap individu sejak zaman dahulu. Hingga saat ini hampir disetiap rumah tangga, kegiatan melipat pakaian masih menggunakan cara tradisional, hal ini tentu menyita waktu dan tenaga. Apalagi jika pekerjaan tersebut dilakukan oleh pelaku usaha di bidang konveksi ataupun laundry, dimana jumlah pakaian yang perlu dilipat sangat banyak setiap harinya. Hal ini dapat berpotensi menghambat efektifitas waktu dalam urusan bisnis dan berpotensi meningkatkan biaya pengeluaran untuk membayar tenaga pekerja yang bertugas untuk melipat pakaian tersebut. Oleh karena itu, penelitian ini bertujuan untuk membuat sebuah simulasi alat pelipat pakaian otomatis dengan menerapkan konsep Finite State Automata (FSA). Penelitian ini diharapkan dapat menghasilkan suatu tata bahasa yang tepat untuk perancangan sebuah simulasi alat pelipat pakaian secara otomatis.
\end{abstract}

\section{Kata Kunci- Pakaian, Konsep Alat Pelipat, Simulasi, Finite State Automata}

\begin{abstract}
The primary needs of every human being are clothing, food and shelter, so these three aspects are indicators of a person's or community's minimum standard of living. Clothing is the most basic need for every human being as a social being. The activity of folding clothes is a very common thing for every individual since time immemorial. Until now, in almost every household, the activity of folding clothes still uses the traditional way, this is of course time and effort. Especially if the work is carried out by business actors in the convection or laundry sector, where the number of clothes that need to be used is very large every day. This can hinder time-effectiveness in business and increase the cost of paying workers who work to folding the outfit. Therefore, this study aims to create a simulation of an automatic clothes folding device by applying the concept of Finite State Automata (FSA). This research is expected to produce an appropriate grammar for the design of a simulation of an automatic clothes folding device.
\end{abstract}

\section{Keywords-Clothes, Folding Machine Concept, Simulation, Finite State Automata}


Jurnal Ilmiah Ilmu Komputer Vol. 7, No. 2, September 2021

Fakultas Ilmu Komputer

Universitas AL Asyariah Mandar

\section{PENDAhuluan}

Teknologi hingga saat ini telah berkembang cukup pesat, sehingga banyak bermunculan inovasi yang diciptakan untuk mempermudah pekerjaan sehari-hari. Salah satu penerapan teknologi yang telah banyak dikembangkan adalah mesin otomatis. Secara umum, sebuah mesin otomatis bertujuan untuk mengubah kegiatan yang biasa dilakukan secara manual dapat menjadi otomatis terutama untuk mempercepat proses pembuatan barang dan menghasilkan produk yang lebih berkualitas[1]. Salah satu penerapan mesin otomatis adalah terciptanya sebuah vending machine. Sebuah vending machine atau mesin penjualan otomatis merupakan mesin elektronika yang digunakan untuk menjual produk seperti makanan, minuman, rokok dan berbagai produk lainnya[2]. Transaksi jual beli tersebut dapat berlangsung ketika sejumlah uang telah dimasukkan ke dalam mesin, setelah itu vending machine akan otomatis mengeluarkan produk yang telah di pilih.

Kebutuhan primer setiap manuasia adalah sandang, pangan dan papan, sehingga ketiga aspek tersebut merupakan indikator standar kehidupan minimum seseorang atau komunitas[3]. Sandang merupakan kebutuhan akan pakaian yang diperlukan oleh setiap manusia[4]. Dengan demikian, kegiatan melipat pakaian merupakan hal yang sangat umum dilakukan setiap individu sejak dahulu kala. Hingga saat ini hampir disetiap rumah tangga, kegiatan melipat pakaian masih menggunakan cara tradisional, hal ini tentu menyita waktu dan tenaga khususnya oleh pelaku usaha di bidang konveksi maupun jenis usaha laundry dimana jumlah pakaian yang perlu dilipat sangat banyak setiap harinya. Hal ini tentu cukup berpotensi menghambat efektifitas waktu dalam urusan bisnis dan meningkatkan biaya pengeluaran untuk membayar tenaga pekerja yang bertugas untuk melipat pakaian-pakaian tersebut.

Oleh karena itu, penelitian ini bertujuan untuk membuat sebuah simulasi alat pelipat pakaian otomatis dengan menerapkan konsep Finite State Automata (FSA). Penelitian ini diharapkan dapat menghasilkan suatu grammar atau tata bahasa yang tepat untuk perancangan sebuah simulasi alat pelipat pakaian secara otomatis. Dengan demikian, kegiatan melipat pakaian yang selama ini dilakukan secara tradisional (manual) dapat dilakukan secara otomatis sehingga dapat mengurangi beban waktu dan tenaga.

\section{TINJAUAN PUSTAKA}

Sebuah penelitian yang membandingkan efektifitas waktu pada saat melipat pakaian secara manual dan menggunakan bantuan alat telah dilakukan sebelumnya. Sebanyak 20 baju yang di jadikan percobaan, tercatat dengan cara pelipatan manual memerlukan waktu 5 menit 58 detik, sedangkan jika menggunakan bantuan alat tersebut hanya memerlukan waktu 3 menit 58,8 detik[5]. Dari hasil yang diperoleh pada penelitian tersebut, maka dapat di simpulkan cukup menyita waktu untuk melipat pakaian secara tradisional sehingga semakin banyak pakaian yang akan di lipat maka semakin banyak tenaga dan waktu yang harus dikeluarkan. Oleh sebab itu, diperlukan sebuah inovasi untuk mempermudah dan meringankan kegiatan melipat pakaian.
(P) ISSN 2442-451X

(O) ISSN 2503-3832

Berkaitan dengan inovasi, terdapat penelitian yang telah berhasil mengimplementasikan alat pelipat pakaian otomatis berbasis mikrokontroler yang mampu beroperasi dengan tiga mode pelipatan[6]. Alat tersebut menghasilkan output berupa beberapa mode pelipatan. Mode 1 digunakan untuk melipat celana panjang dan celana pendek, mode pelipatan 2 untuk melipat handuk dan mode pelipatan 3 digunakan untuk melipat baju dan kemeja. Dari ketiga mode pelipatan tersebut telah dilakukan sebanyak lima kali percobaan (testing) dengan hasil rata-rata 2,31 detik untuk mode pelipatan 1 , kemudian 4,77 detik untuk mode pelipatan 2 dan tercatat 7,16 detik untuk mode pelipatan 3 .

Berdasarkan hasil kecepatan kinerja alat, penelitian yang berjudul alat pelipat pakaian otomatis berbasis mikrokontroler lebih cepat jika dibandingkan dengan alat serupa yang telah dikembangkan sebelumnya yaitu alat pelipat pakaian otomatis berbasis pengendali mikro, yang tercatat membutuhkan waktu diatas 10 detik untuk melipat baju maupun celana[7]. Kedua alat yang telah di uraikan diatas memiliki kesamaan dimana alat pelipat pakaian tersebut masih semi otomatis, Ketika proses pelipatan selesai maka pengguna harus segera mengambil pakaian tersebut dan meletakkan pakaian lainnya untuk dilipat kembali. Namun kedua penelitian tersebut telah berhasil membantu meringankan pekerjaan melipat pakaian berdasarkan hasil perbandingan waktu pelipatan yang telah di uji.

Teori automata merupakan teori mengenai mesinmesin abstrak, dan berkaitan erat dengan teori bahasa formal[8]. Automata dapat dianggap sebagai mesin memori dan setiap input pada mesin automata dianggap sebagai bahasa yang harus dikenali oleh sebuah mesin[9]. Finite State Automata (FSA) merupakan suatu pemodelan matematika yang menerima input kemudian menghasilkan output dimana mesin ini memiliki jumlah state terbatas dan dapat berpindah dari satu kondisi ke kondisi yang berbeda berdasarkan fungsi input dan transisi[10].

FSA terdiri dari dua jenis yaitu Deterministic Finite Automata (DFA) dan Non-Deterministic Automata (NFA), keduanya dibedakan dari segi arah transisi state. DFA hanya memiliki satu arah transisi state, sedangkan NFA dapat memiliki lebih dari satu arah transisi[11]. Perbedaan lainnya adalah DFA tidak dapat menerima input kosong (empty), sedangkan NFA dapat menerima input kosong. Sebuah FSA biasanya dirancang dalam bentuk NFA, dan ditransformasi ke bentuk DFA untuk menghasilkan bentuk yang lebih minimal dan efisien[12]. Secara formal, sebuah FSA memiliki 5 tupel yang dapat di definisikan pada tabel berikut:

Tabel 1. Definisi Tupel FSA

\begin{tabular}{cl}
\hline Tupel & \multicolumn{1}{c}{ Definisi } \\
\hline $\mathrm{Q}$ & Himpunan state/kedudukan \\
$\sum$ & Himpunan simbol input/masukan/abjad \\
$\delta$ & Fungsi transisi \\
$\mathrm{S}$ & State awal (initial state) \\
$\mathrm{F}$ & State akhir, F $\cap \mathrm{Q}$ (jumlah state akhir pada \\
& suatu FSA bisa lebih dari satu) \\
\hline
\end{tabular}


Jurnal Ilmiah Ilmu Komputer Vol. 7, No. 2, September 2021

Fakultas Ilmu Komputer

Universitas AL Asyariah Mandar

Penerapan konsep FSA telah banyak digunakan di berbagai penelitian-penelitian sebelumnya sebagai dasar alur kerangka kerja sebuah mesin otomatis. Contohnya adalah desain vending machine penjualan rokok yang terintegerasi dengan e-KTP, yang bertujuan untuk mengurangi jumlah pembeli rokok dibawah umur[13]. Penerapan konsep FSA pada penelitian kali ini akan berbeda dengan cara kerja sebuah vending machine pada umumnya karena desain konsep simulasi alat pelipat pakaian otomatis ini tidak menggunakan inputan uang untuk pengoperasiannya.

\section{METODE YANG DIUSULKAN}

Metode penelitian yang diusulkan adalah metode prototyping dan formal methods (metode formal). Kedua metode yang digunakan dapat diuraikan sebagai berikut:

\subsection{Metode Prototyping}

Metode prototyping merupakan proses purwarupa sebuah perangkat lunak yang hasilnya belum tentu sama dengan hasil akhir[1]. Metode ini sangat umum digunakan dalam mengembangkan sebuah perangkat lunak walaupun spesifikasi kebutuhan untuk perancangan belum lengkap dan belum jelas diketahui. Alur sebuah metode prototyping dapat dilihat pada gambar berikut:

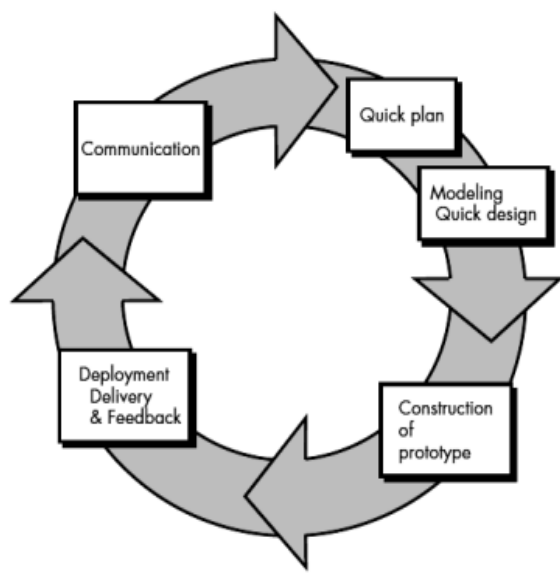

Gambar 1. Alur metode prototyping

Berdasarkan gambar diatas, terdapat lima tahapan yang harus terpenuhi, diantaranya sebagai berikut:

\section{a. Communication}

Komunikasi merupakan tahap awal dari metode prototyping untuk mengidentifikasi permasalahan dan mengumpulkan berbagai informasi untuk memenuhi kebutuhan penelitian. Data diperoleh dari berbagai literatur dan penelitian terdahulu sebagai referensi tentang penerapan konsep FSA untuk perancangan simulasi mesin otomatis.

\section{b. Quick Plan}

Menyusun perencanaan secara cepat untuk menentukan fokus objek penelitian, hal ini sekaligus menentukan batasan masalah, dimana tiga jenis pakaian yang akan dijadikan objek penelitian adalah baju, celana dan kemeja. Setelah itu, melakukan observasi lebih lanjut untuk mengetahui secara detail pola dan gerakan yang umum dilakukan dalam menerapkan pelipatan pada ketiga jenis objek tersebut.

\section{c. Modelling Quick Design}

Setelah mempelajari dan menentukan pola pelipatan ketiga jenis pakaian yang dijadikan objek, maka langkah selanjutnya adalah membuat kerangka desain simulasi perangkat keras yang akan digunakan untuk meniru pola gerakan pelipatan ketiga jenis objek tersebut.

\section{d. Construction of Prototyping}

Mengembangkan prototype sesuai dengan kerangka desain yang telah di identifikasi sebelumnya. Pada tahap ini, konstruksi purwarupa simulasi alat pelipat pakaian otomatis sudah dapat digambarkan dengan jelas, dilengkapi dengan fungsi-fungsi dan komponen yang diperlukan untuk pengoperasian simulasi alat pelipat pakaian otomatis.

\section{e. Deployment Delivery \& Feedback}

Melakukan pengujian dan evaluasi pada simulasi alat yang telah dirancang, sehingga dapat mengetahui apakah simulasi alat tersebut sudah berjalan sesuai tujuan atau belum. Jika belum sesuai, akan dilakukan pengecekan dan perbaikan lebih lanjut sehingga feedback yang diterima memberikan hasil yang positif dan sesuai dengan tujuan.

\subsection{Metode Formal}

Metode formal merupakan suatu pemodelan matematika yang dapat digunakan untuk menjembatani pembuatan, pengembangan dan verifikasi perangkat keras dan piranti lunak yang dapat digunakan dari perancangan awal hingga pengujian hasil[14]. Metode formal pada penelitian ini berorientasi model, yaitu dengan membuat suatu model perilaku sistem menggunakan obyek matematika seperti set dan urutan, diantaranya state diagram dan automata model teoritis. Diagram state digunakan sebagai kerangka desain untuk sebuah state machine dan dapat memudahkan proses pengembangan dan memahami fungsi-fungsi pada saat menggunakan mesin[15]. Dalam menerapkan metode formal, diperlukan sebuah kerangka penelitian untuk menentukan alur penelitian secara terstruktur dan komperhensif. Langkah-langkah kerangka penelitian ini dapat dilihat pada gambar berikut:

Analisa Proses Bisnis

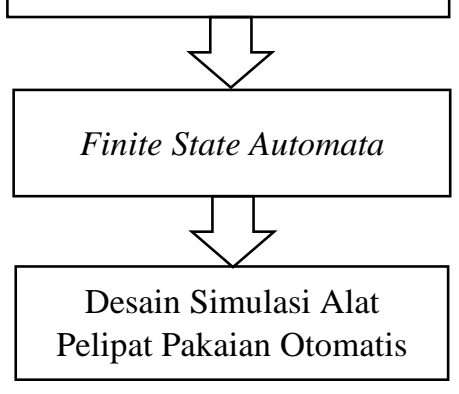

Gambar 2. Kerangka Penelitian 
Jurnal Ilmiah Ilmu Komputer Vol. 7, No. 2, September 2021

Fakultas Ilmu Komputer

Universitas AL Asyariah Mandar

Berdasarkan kerangka penelitian diatas, terdapat tiga aspek yang harus dilakukan, diantaranya sebagai berikut:

\section{a. Analisa Proses Bisnis}

Simulasi alat ini memiliki batasan inputan pakaian berupa baju, celana dan kemeja, hal ini merupakan pengembangan dari tahap quick plan yang telah ditentukan pada metode prototyping. Untuk mempermudah analisa proses bisnis, alur kerja simulasi alat ini dituangkan ke dalam sebuah flowchart pada gambar 3 berikut ini:

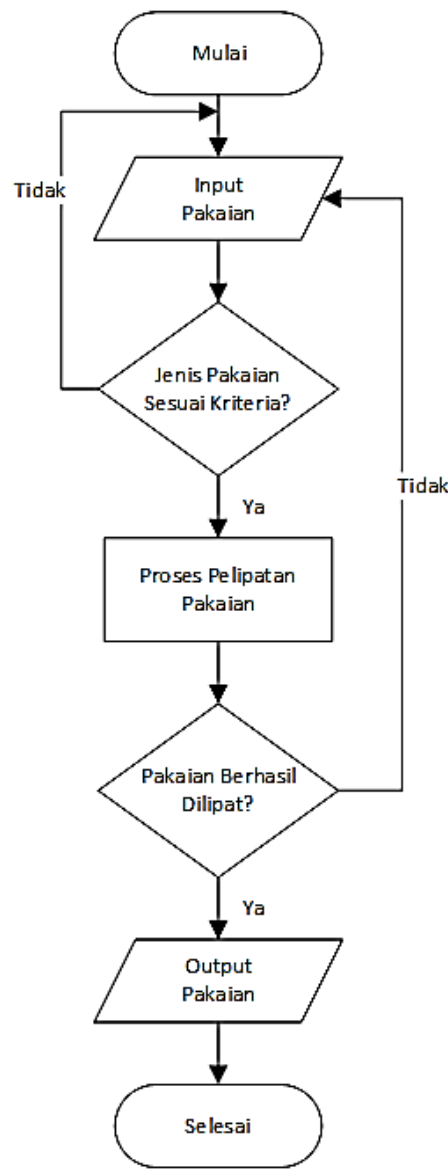

Gambar 3. Flowchart proses bisnis

Berdasarkan gambar diatas, perancangan proses bisnis menggunakan dua tahap validasi yang diterapkan yaitu kesesuaian jenis pakaian yang di input dan pengecekan keberhasilan proses pelipatan yang dilakukan. Artinya, bila salah satu atau kedua proses validasi tersebut tidak terpenuhi maka proses pelipatan tidak akan berhasil.

\section{b. Finite State Automata}

Pada tahap ini seluruh alur proses bisnis yang telah ditentukan akan dituangkan ke dalam serangkaian diagram state. Diagram state FSA simulasi alat pelipat pakaian otomatis ini menggunakan jenis FSA non-deterministik (NFA) dengan mempertimbangkan cara kerja dan karakteristik simulasi mesin yang dirancang. Perancangan diagram FSA dapat dilihat pada gambar berikut:

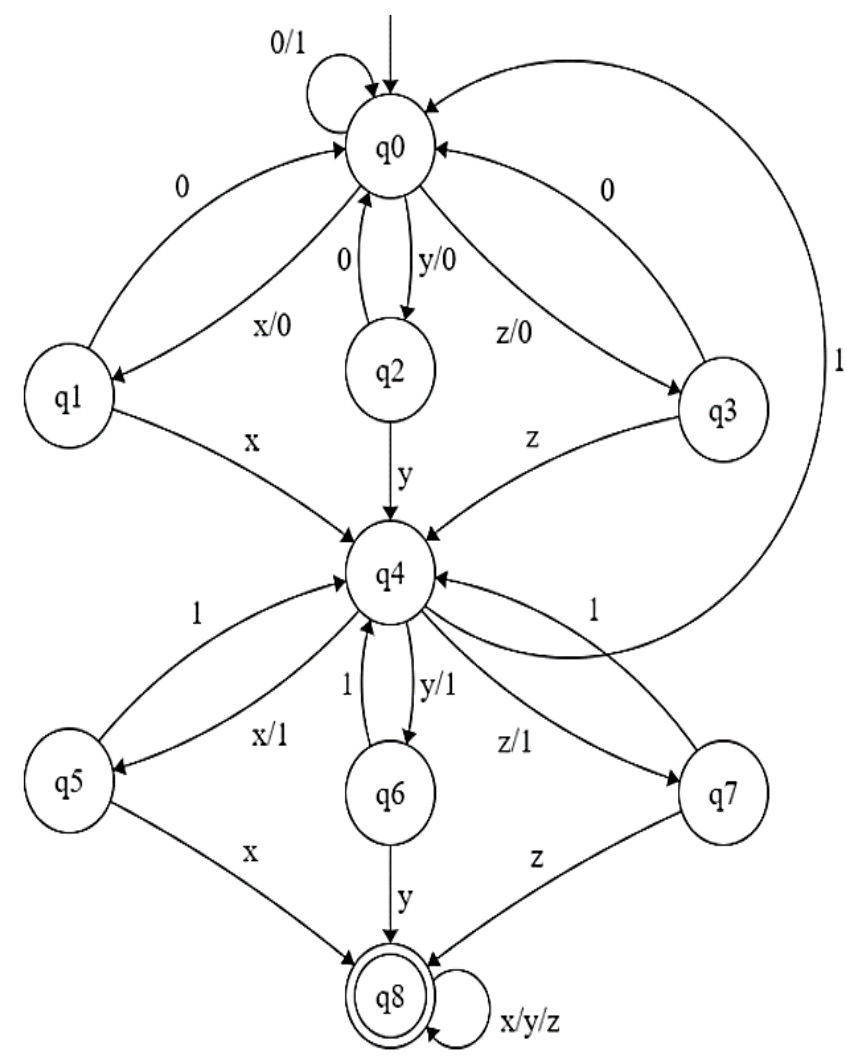

Gambar 4. Diagram state

Gambar diagram state diatas secara formal dapat di definisikan bahwa $\mathrm{Q}=\{\mathrm{q} 0, \mathrm{q} 1, \mathrm{q} 2, \mathrm{q} 3, \mathrm{q} 4, \mathrm{q} 5, \mathrm{q} 6, \mathrm{q} 7, \mathrm{q} 8\}, \Sigma=$ $\{0,1, \mathrm{x}, \mathrm{y}, \mathrm{z}\}, \mathrm{S}=\mathrm{q} 0, \mathrm{~F}=\mathrm{q} 8$. Berdasarkan definisi tersebut, transisi diagram state dapat dilihat pada tabel berikut:

Tabel 2. Transisi diagram state

\begin{tabular}{cccccc}
\hline$\delta$ & 0 & 1 & $\mathrm{x}$ & $\mathrm{y}$ & $\mathrm{z}$ \\
\hline $\mathrm{q} 0$ & $\{\mathrm{q} 0, \mathrm{q} 1, \mathrm{q} 2, \mathrm{q} 3\}$ & $\{\mathrm{q} 0\}$ & $\varnothing$ & $\varnothing$ & $\varnothing$ \\
$\mathrm{q} 1$ & $\{\mathrm{q} 0\}$ & $\varnothing$ & $\{\mathrm{q} 4\}$ & $\varnothing$ & $\varnothing$ \\
$\mathrm{q} 2$ & $\{\mathrm{q} 0\}$ & $\varnothing$ & $\varnothing$ & $\{\mathrm{q} 4\}$ & $\varnothing$ \\
$\mathrm{q} 3$ & $\{\mathrm{q} 0\}$ & $\varnothing$ & $\varnothing$ & $\varnothing$ & $\{\mathrm{q} 4\}$ \\
$\mathrm{q} 4$ & $\varnothing$ & $\{\mathrm{q} 0\}$ & $\{\mathrm{q} 5\}$ & $\{\mathrm{q} 6\}$ & $\{\mathrm{q} 7\}$ \\
$\mathrm{q} 5$ & $\varnothing$ & $\{\mathrm{q} 4\}$ & $\{\mathrm{q} 8\}$ & $\varnothing$ & $\varnothing$ \\
$\mathrm{q} 6$ & $\varnothing$ & $\{\mathrm{q} 4\}$ & $\varnothing$ & $\{\mathrm{q} 8\}$ & $\varnothing$ \\
$\mathrm{q} 7$ & $\varnothing$ & $\{\mathrm{q} 4\}$ & $\varnothing$ & $\varnothing$ & $\{\mathrm{q} 8\}$ \\
$\mathrm{q} 8$ & $\varnothing$ & $\varnothing$ & $\{\mathrm{q} 8\}$ & $\{\mathrm{q} 8\}$ & $\{\mathrm{q} 8\}$ \\
\hline
\end{tabular}

Diagram state diatas menunjukkan bahwa terdapat dua tahap validasi yang diterapkan untuk meminimalisir potensi kesalahan yang mungkin terjadi. Validasi tahap pertama terdapat pada state q1 (baju), q2 (celana), dan q3 (kemeja). Jika jenis inputan yang diberikan tidak sesuai kriteria yang telah ditentukan, maka state $\mathrm{q} 1, \mathrm{q} 2$ dan $\mathrm{q} 3$ akan mengembalikan inputan tersebut ke state awal. Kemudian, jika jenis pakaian telah sesuai dengan kriteria maka state q1, $\mathrm{q} 2$ dan $\mathrm{q} 3$ akan melanjutkan proses ke state q4. State $\mathrm{q} 4$ merupakan state untuk menjalankan validasi tahap kedua, 
Jurnal Ilmiah Ilmu Komputer Vol. 7, No. 2, September 2021

Fakultas Ilmu Komputer

Universitas AL Asyariah Mandar

karena $\mathrm{q} 4$ akan memisahkan lebih rinci jenis pakaian yang diterima. Proses validasi tahap kedua dari state $\mathrm{q} 4$ berlanjut ke state q5 (baju), q6 (celana) dan q7 (kemeja) untuk dilakukan proses pelipatan. Jika proses pelipatan berhasil, baik di state q5, q6 atau q7, maka akan diteruskan di q8 (final state). Namun jika proses pelipatan gagal, maka akan dikembalikan ke state $\mathrm{q} 4$, kemudian diteruskan ke q0 (state awal). Identifikasi state, uraian simbol dan keterangan input/output dapat dilihat pada tabel 3 dibawah ini:

Tabel 3. Identifikasi input, output dan state

\begin{tabular}{clc}
\hline Simbol & \multicolumn{1}{c}{ Uraian } & Jenis \\
\hline 0 & $\begin{array}{l}\text { Jenis pakaian tidak memenuhi } \\
\text { kriteria yang telah di definisikan }\end{array}$ & Input \\
1 & $\begin{array}{l}\text { Proses pelipatan gagal } \\
\text { x }\end{array}$ & Memberikan inputan baju \\
y & Memberikan inputan celana & Input \\
z & Memberikan inputan kemeja & Input \\
q0 & State awal (initial state) & Start State \\
q1 & Menerima inputan baju & State \\
q2 & Menerima inputan celana & State \\
q3 & Menerima inputan kemeja & State \\
q4 & Menerima inputan sesuai kriteria & State \\
q5 & Menerima inputan baju dan & State \\
& memulai proses pelipatan & \\
q6 & Menerima inputan celana dan & State \\
& memulai proses pelipatan & \\
q7 & Menerima inputan kemeja dan & State \\
& memulai proses pelipatan & \\
q8 & Menerima pakaian yang berhasil & Output / \\
& terlipat dan mengeluarkannya & Final State \\
\hline
\end{tabular}

\section{c. Desain Simulasi Alat Pelipat Pakaian}

Desain simulasi alat pelipat pakaian ini dibuat sesederhana mungkin (user friendly), hal ini bertujuan untuk mempermudah pengguna pada saat mengoperasikannya.

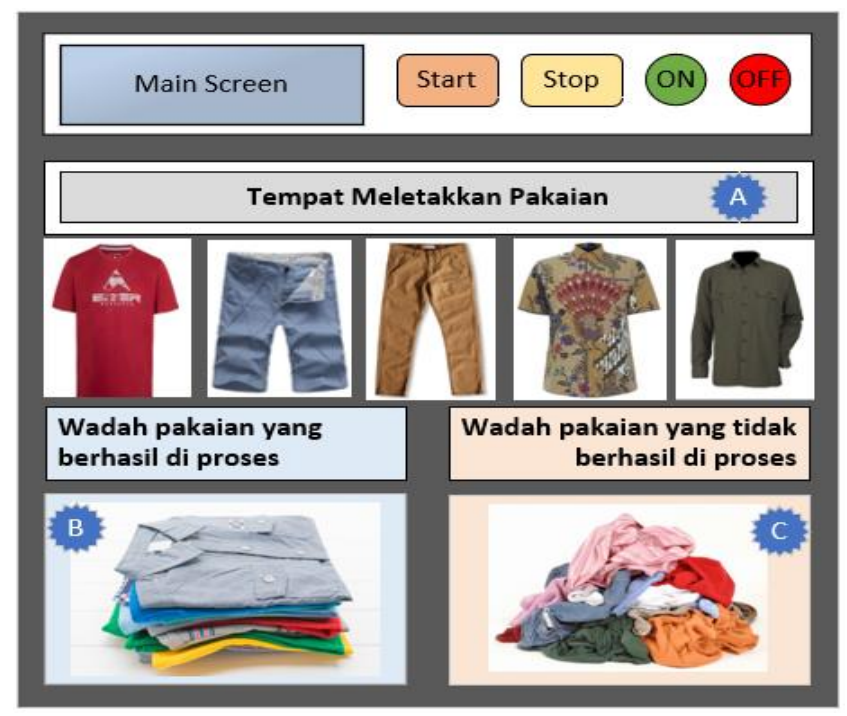

Gambar 5. Desain Simulasi Alat Pelipat Pakaian
(P) ISSN 2442-451X

(O) ISSN 2503-3832

Pada gambar diatas, terlihat beberapa komponen yang digunakan diantaranya adalah tombol on / off yang berfungsi untuk menyalakan dan mematikan alat (pemutus aliran listrik). Tombol start / stop digunakan untuk memulai dan menghentikan proses pelipatan pakaian, kemudian terdapat satu layar utama (main screen) yang berfungsi untuk menampilkan berbagai informasi saat alat ini dioperasikan. Selain itu, terdapat tiga buah wadah yang digunakan yaitu, wadah A digunakan sebagai jalur input untuk memasukkan pakaian yang akan dilipat, kemudian wadah B yang berfungsi sebagai jalur output untuk mengeluarkan pakaian yang berhasil di lipat dan wadah $\mathrm{C}$ digunakan untuk mengeluarkan output untuk jenis pakaian yang tidak sesuai kriteria dan pakaian yang tidak berhasil di lipat oleh mesin.

\section{HASIL PENELITIAN}

Berdasarkan perancangan FSA non-deterministik yang telah diterapkan, terlihat bahwa hubungan antar state sangat mempengaruhi hasil yang diberikan. sehingga setiap state memiliki pola tersendiri untuk melakukan proses pelipatan berdasarkan jenis pakaian yang di input. Hal ini bertujuan agar simulasi alat ini tidak dapat melakukan pola pelipatan secara sembarang. Teknik pengujian konsep FSA dilakukan dengan cara membuat tabel hasil pengujian dari beberapa kondisi yang memungkinkan terjadi kesalahan pada simulasi alat yang telah dirancang. Tabel hasil pengujian simulasi alat pelipat otomatis ini dapat dilihat sebagai berikut:

Tabel 4. Hasil Pengujian

\begin{tabular}{|c|c|c|}
\hline Fungsi & Pengujian & Hasil \\
\hline Input baju & $\begin{array}{l}\text { Kesesuaian hasil pola } \\
\text { pelipatan pada baju }\end{array}$ & Baik \\
\hline Input celana & $\begin{array}{l}\text { Kesesuaian hasil pola } \\
\text { pelipatan pada celana }\end{array}$ & Baik \\
\hline Input kemeja & $\begin{array}{l}\text { Kesesuaian hasil pola } \\
\text { pelipatan pada kemeja }\end{array}$ & Baik \\
\hline $\begin{array}{l}\text { Input pakaian } \\
\text { yang tidak sesuai } \\
\text { kriteria }\end{array}$ & $\begin{array}{l}\text { Alat tidak menjalankan } \\
\text { proses pelipatan apapun }\end{array}$ & Baik \\
\hline $\begin{array}{l}\text { Tempat pakaian } \\
\text { wadah A (input) }\end{array}$ & $\begin{array}{l}\text { Memproses penarikan } \\
\text { pakaian yang di input }\end{array}$ & Baik \\
\hline $\begin{array}{l}\text { Tempat pakaian } \\
\text { wadah B (output) }\end{array}$ & $\begin{array}{l}\text { Mengeluarkan pakaian } \\
\text { yang berhasil dilipat } \\
\text { dengan tertumpuk rapih }\end{array}$ & Baik \\
\hline $\begin{array}{l}\text { Tempat pakaian } \\
\text { wadah C (output) }\end{array}$ & $\begin{array}{l}\text { Mengeluarkan pakaian } \\
\text { yang gagal di proses }\end{array}$ & Baik \\
\hline Tombol on/off & $\begin{array}{l}\text { Alat dapat menyala dan } \\
\text { mati sesuai perintah. }\end{array}$ & Baik \\
\hline Tombol start/stop & $\begin{array}{l}\text { Alat dapat memulai dan } \\
\text { menghentikan proses } \\
\text { pelipatan. }\end{array}$ & Baik \\
\hline $\begin{array}{l}\text { Layar utama } \\
\text { (Main screen) }\end{array}$ & $\begin{array}{l}\text { Menampilkan berbagai } \\
\text { informasi berdasarkan } \\
\text { tombol yang di input. }\end{array}$ & Baik \\
\hline
\end{tabular}


Jurnal Ilmiah Ilmu Komputer Vol. 7, No. 2, September 2021

Fakultas Ilmu Komputer

Universitas AL Asyariah Mandar

\section{KESIMPULAN}

Berdasarkan pengujian yang telah dilakukan, dapat di simpulkan bahwa penerapan konsep FSA dapat diandalkan untuk perancangan simulasi alat pelipat pakaian otomatis. Konsep FSA diterapkan untuk menangkap pola inputan yang diberikan dan membaca simbol inputan tersebut menjadi suatu bahasa yang dapat dikenali oleh sebuah mesin otomatis. Selain itu, penerapan konsep FSA memiliki akurasi yang tinggi, sehingga input dan output dapat terealisasi sesuai rencana. Dengan demikian, penggunaan FSA sebagai dasar perancangan sebuah mesin otomatis telah berhasil mendefinisikan fungsi-fungsi yang dirancang secara detail dan akurat, sehingga proses pelipatan pada baju, celana dan kemeja dapat disimulasikan dengan baik dan benar.

\section{UCAPAN TERIMA KASIH}

Penulis mengucapkan terima kasih kepada seluruh pihak yang telah terlibat dalam penelitian ini. Dengan segala keterbatasan ditengah wabah covid-19 yang mengharuskan aktivitas bekerja dan belajar dari rumah, semoga bukan menjadi penghalang untuk tetap semangat menuntut ilmu.

\section{Daftar Pustaka}

[1] Fergie Joanda Kaunang., 2019, Penerapan Konsep Finite State Automata (FSA) pada Mesin Pembuat Ice cream Otomatis, Jurnal TeIK., Vol. 9, No. 2.

[2] Prio Handoko, Hendi Hermawan, Safitri Jaya., 2018, Reverse Vending Machine Penukaran Limbah Botol Kemasan Plastik Dengan Tiket Sebagai Alat Tukar Mata Uang, Seminar Nasional Sains dan Teknologi., ISSN 2407-1846.

[3] Daud Bahransyaf., 2017, Kemiskinan di Banda Aceh, Jurnal PKS Kemensos RI, Vol. 16, No. 1, 43-56.

[4] Dewi Yulianti, Suryana, Asep Yanyan Setiawan., 2018, Hubungan Konsep Geografi dengan Pengembangan Usaha Konveksi serta Kesejahteraan Masyarakat di Desa Cilame Kecamatan Kutawaringin Kabupaten Bandung, Jurnal Geoarea, Vol. 1, No. 1, 27-31.

[5] Erwin Sukma Bukardi, Wahyu Setyo Pambudi., 2015, Perancangan dan Pembuatan Semi Automatic T-shirt Folding Machine menggunakan Metode Fuzzy Proportional Derivative (FPD), Jurnal Sains dan Teknologi Vol. 1, No. 1, ISSN 2460-173X.

[6] Elisa Heriyanti, Gumelar Tambunan, Regi A. Saputra, Noor C. Basjaruddin, E. Rakhman., 2020, Alat Pelipat Pakaian Otomatis Dengan Tiga Mode Pelipatan Berbasis Mikrokontroler, Prosiding The 11th Industrial Research Workshop and National Seminar, Bandung.

[7] Abim Nurcahyo, M. Ibrahim Ashari, Sotyohadi., 2019, Alat Pelipat Pakaian Otomatis Berbasis Pengendali Mikro, Seminar Hasil Elektro Institut Teknologi Nasional Malang.
(P) ISSN 2442-451X

(O) ISSN 2503-3832

[8] Ma'arif, Ridwan Ahmad dan Fauziah., 2018, Implementasi Finite State Automata (FSA) dalam Proses Pengisian Kartu Rencana Studi Teknik Informatika Universitas Nasional Jakarta, Journal of Information Technology and Computer Science (JOINTECS), Vol. 3, No. 3, 255-260.

[9] Aidil Ahmat., 2018, Pengantar Teori Bahasa Formal, Otomata dan Komputasi, Deepublish, Yogyakarta.

[10] Y. M. R. Putra, 2017, Sentence Analysis with Artificial Intelligence Machine Learning Using Finite State Automata, PROXIES, vol. 1, no. 1, 1-6.

[11] R. A. Nugraha, A. Mulyani, W. Gata., 2020, Desain Vending Machine Rujak Buah Dengan Finite State Automata, Indonesian Journal on Computer and Information Technology, Vol. 5, No. 2, 198-207.

[12] Dimas Dandy Aryarajendra Suprapto, Fauziah., 2020, Implementasi Finite State Automata Pada Mesin Abstrak DFA dan NFA Berbasis Android, Jurnal Satuan Tulisan Riset dan Inovasi Teknologi, Vol. 5, No. 1, 28-36.

[13] Gabriel Vangeran Saragih, Anas Faisal, W. Gata., 2020, Desain Vending Machine Rokok Dengan Mengimplementasikan Finite State Automata Terintegrasi Dengan E-KTP, Jurnal Ilmu Komputer dan Teknologi Informasi, Vol. 12, No. 1, 55-60.

[14] Ririn Suharsih, Firas Atqiya., 2019, Penerapan Konsep Finite State Automata (FSA) pada Aplikasi Simulasi Vending Machine Yoghurt Walagri, Jurnal Pendidikan Multimedia, Vol. 1, No. 2, 71-78.

[15] Sujana, D., Sari, K.M., \& Ulum, N.M., 2018, Analisa Sistem Dan Implementasi Pada Vending Machine Red Boks Di Gedung A UNIS Tangerang Dengan Menggunakan Metode Finite State Automata (FSA), JUTIS, Vol. 6, No. 2, ISSN 2252-5351. 